\title{
Research on Teaching Pattern Based on Internet Plus
}

\author{
Yulan Zhao ${ }^{1, ~ a ~ a n d ~ C h u n f e n g ~ J i a n g ~}{ }^{2, b^{*}}$ \\ 1,2 Jilin Agricultural Science and Technology University, Jinlin China \\ allbird@126.com, bhero_jcf@126.com
}

Keywords: Internet plus; Teaching pattern; Autonomous learning; Collaborative learning

\begin{abstract}
Internet plus strategy was listed as a national strategy, exploring the new teaching pattern became the demand of education in the new era. This paper carried on the detailed analysis about the basic characteristics of the Internet plus teaching pattern, and the proposals of constructing teaching pattern based on Internet plus including teaching preparation, learning process, summary and promotion, feedback and evaluation were put forward.
\end{abstract}

\section{Introduction}

In 2015, the Internet plus strategy was listed as a Chinese national strategy; the whole society explored actively the new supply model of educational services. The government encouraged schools to use digital educational resources and service platform, to gradually explore a new model of network education, to promote the development of online educational curriculum resource sharing. And the state incited them to popularize learning model of massive open online courses such as network promotion, to probe establishing a network of learning credits and credit transfer system, to accelerate the transformation of service pattern of higher education [1]. Internet plus education had become the development of modern education. The Internet plus education need Internet ability through Internet technology, to become a new impetus to the education, and then to promote the whole social education resources being plentiful, to expand high-quality educational resources coverage, making education more open, making a solid foundation for lifelong learning society.

\section{Basic Characteristics of the Internet plus Teaching Pattern}

The Internet plus had brought a revolutionary impact and challenges to the traditional teaching pattern, Internet plus education was not a simple superposition of Internet technology and educational technology, but the update of organization model in the process of teaching and learning [2]. In the traditional education, the core of the first generation of education was books, and it of second generation education was materials, the third generation, it was in case of guidance and cases. Now, the fourth generation education focused on student really. In the classroom, two years ago, it would be confiscated if someone played mobile phone, and today, students were using the Internet in learning and innovation and entrepreneurship practice, this way could really stimulate students' learning enthusiasm and innovation potential. Internet plus education was to train the thinking model as the guide, to develop creative thinking of students. Through inspiration, development and training, it finally realized financial depth between the Internet and the education. The teaching pattern based on the Internet plus had some characteristics as followed.

Educational Resources Opening to the Outside World. Under the traditional teaching model, education resources were concentrated in the classroom, library, and lab, only to meet the needs of students. While in the Internet plus teaching pattern, Internet stored vast amounts of knowledge and information, became a huge information base. And with Internet users continued to upload, release, its capacity was expanded persistently. By means of Internet technology, educational resources could across the campus geographical limitations, to cover every corner of the world. MOOCS, the massive open online courses, was the Internet educational product, which provided a platform for students 
around the world to share quality of university educational resources through the Internet in real-time [3].

Students Autonomous Learning. Under traditional teaching mode, students prepared lessons before class passively, went to classes which were designated locations in accordance with the curriculum, and reviewed after class to prepare for the exam. In the Internet plus teaching pattern, students could study anytime and anywhere as long as the network connection, no longer depended entirely on the classroom and textbooks. The Internet plus teaching pattern broke through the limitations of the campus, realized the freedom of space and time, which fully embodied the autonomy of study [4]. For example, in MOOCS classroom, students could choose courses with pesonal interest. They could choose upload their learning experience to the Internet to share with others, and they would evaluate the learning process and learning outcomes themselves or appraised by each other [5].

Students as the Center of Learning. The student was the center of learning process in the Internet plus teaching pattern. The provider of the courses was the teachers, but the teaching process was around the students' needs and personal preferences, and the teacher was the subject but the student was the center. Students and teachers designed teaching and learning programs cooperatively. The students chose their own way and process of learning, according to the knowledge module and application software from the Internet plus platform. On the network system, the students would preview video, difficulties of the course, independently before class. It established a learning space before the class time, which formed a more strict learning organization. In classroom, teachers organized the high quality teaching activities; let students learn to apply content in the specific environment, help students to cultivate the ability of solving problems independently.

Diversification of Teaching Methods. The Internet plus teaching pattern broke through the traditional teaching unit in classroom. The students could select contents of the cell on the networks which teachers pre-recorded to study autonomously [6,7]. They could communicate with other students and teachers online, to complete the task of preview. In application session, students might choose network classroom simulation training, and then completed application and internalization of knowledge unit online. The students could also choose the classroom which teaching environment was set by teachers offline, to participate in the discussion, practice, application and research activities, they would complete digestion and absorption of knowledge through a combination of online and offline.

Teaching Evaluation More Reasonable. The Internet plus teaching pattern was a process about teaching data acquisition, some unstructured data outside test scores were collected, such as practice ability, objective factors etc[8]. It could support the evaluation that comprehensive and system, the connotation and function of teaching evaluation had been expanded. Through the network platform, teachers could evaluate students based on their learning performance; students might also estimate teachers by their teaching effectiveness. At the same time, schools and education departments might analyze and assess teaching and learning performance remotely with database, parents could also know the quality of teaching and their children circumstances from school. In the Internet plus teaching pattern, everyone was the subject of evaluation, and the object of being evaluated, all aspects of society involved in the teaching evaluation was more convenient and more in-depth.

\section{Construction of Internet plus Teaching Pattern}

One of the main tasks of the Internet plus teaching pattern was to construct a personalized and collaborative teaching mode. The traditional teaching environment construction was based on the management of teachers, and emphasized the discipline in the teaching activities must be stable and orderly. Under the environment of Internet plus teaching pattern, student-centered was the main idea which to construct teaching and learning environment. It focused on the development of to individual students, excavated students' autonomous learning potential, acquired knowledge and experience in the process of full cooperation to participate in teaching activities. The Internet plus teaching pattern 
paid attention to students' individual differences, cultivating students' ability to obtain information through the outside world with their own ability to reconstruct the knowledge and experience.

Learning Environment Elements. The Internet plus teaching pattern followed the idea of constructivist, four basic elements, to set up the learning environment, including the teaching situation, tools, resources, architecture. The learning situation in Internet plus teaching pattern based on daily life and practical tasks, which mixed teaching online and offline, designed to meet the diverse social and cultural context and healthy public opinion. The tool included handling tools, processing tools, communication tools, visualization tools. These tools helped teachers design the teaching plan with students as the center, provide multimedia resources, and organize cooperative learning and discussion activities. Which let students accept individualized teaching mode under the guidance of teachers, cultivating their autonomous learning ability [9]. The resources referred to static and dynamic material in multiple forms, such as knowledge fragmentation, teaching strategies and the individual demand meta etc. The organization structure was the form of the knowledge reorganization that according to the individual needs, involving knowledge mapping sequence, and metacognitive knowledge form, program and learning strategies. Teachers would study the combination of environmental factors and the Internet plus teaching pattern. Science to build a real learning environment, it could also stimulate students' learning interest and improve teaching quality.

Teaching Preparation. In this stage, the teachers should form their teaching team about curricula, divide tasks reasonable to team members, and complete the teaching design and course preparation. They must accomplish resource integration and optimization, construction of teaching and tasks scenarios, consultation teaching organization mode online and offline, evaluation methods and content of each learning task [10]. In the teaching design, there must be specific teaching target and personalized requirements, considering the differences of learners. Teaching content should be with sufficient breadth, depth, advanced security and timeliness. The content of teaching in the process of preparing need distinguish the difference between teaching resources online and offline, online video teaching should have the correct length and clarity. To give lectures, the teaching process should be interesting and instructive, and be ready to enter the classroom discuss. The production and selection of teaching resources must fit technical requirements of network platform. Offline teaching adhering to the characteristics of the flipped classroom, it should concern for discuss, practice, application, inquiry, and the participation of the offline learning of individual students, focusing on face to face communication. Setting reasonable question and answer session, it must timely feedback and solve students' problem, organize communication and interaction between online and offline. Teachers should in order to study the development of diversified evaluation methods, which met the requirements of curriculum colleague and third party accreditation.

Self-study before Class. In this session, students could understand the curriculum teaching goal, teaching content and teaching process clearly through the video and multimedia resources from network platform,. The task in virtual classroom, students used pre-recorded video by teachers to learn theory knowledge, practice and test them. They could participate in the self-organizing network discussion, and summarize problem with exploring meaning. The student might complete the initial connection of knowledge application and innovation stage, and the teacher prepared synchronous offline or online virtual classroom to gain collaborative and inquiry based personalized teaching organization. During the whole process, the students used cooperative learning to acquire knowledge and learning experience, to build their knowledge and learning experience.

Classroom Learning. Learning in the classroom, the teacher firstly built a complete clear learning scene, and threw out multiple teaching related learning tasks or topics while using fully negotiation mechanism about teachers and students. Students could choose one of the topics provided by teachers, or independently determine the related topics. Students might choose independent inquiry learning and collaborative learning according to their own learning the ability or the teacher recommended. In the process, teachers could provide personalized guidance, listened and recorded the difficulty of learning, observed the students overall performance, determined whether to achieve the goal of teaching. Students showed their learning outcomes, group communication, could also carry out online 
exchange submitted on the platform. Then the teachers might evaluate the results, explaining and answering questions of difficulty. Finally, the teacher could directly assess the performance of students according to the performance of students, but also could assigned exercises or tests to evaluate the degree of students' knowledge and skills.

Feedback Evaluation. The evaluation was designed with the different characteristics of students, under the environment of Internet plus teaching patern. It emphasized the difference of students, test scene complexity and effectiveness. And it was in various forms, paid attention to learning process evaluation, cumulative learning individual learning status and results data, through large data of individual learning analysis, continued to formulate and adjust the learning plan and habits, promoted the accumulation of personal learning experiences, and ultimately improved the ability of autonomous learning and collaborative learning. It would improve the Internet teaching pattern, and enhance the teaching ability, then promote education reform.

\section{Summary}

The Internet had changed the traditional teaching model, the teacher was no longer the only source of knowledge. The application of modern educational technology turned teacher from the role of leader into assistant, provided learning service. The Internet plus teaching pattern carried the boring theory knowledge on the Internet, students' learning motivation would be excited with vivid images, cooperative learning atmosphere. Teachers help students develop their own learning the rhythm, set the appropriate teaching tasks for students, so as to reduce the poor learning ability of students to form a personalized learning time, learning strategies and implementation procedures. Based on Internet plus teaching pattern, not only could make learning more personalized, more efficient, and the original need to become able to create new value of education to the students of the Internet. The Internet provided learners gained the ability of learning, effective way to meet the self-body learning needs; it made students as the center, selected the appropriate learning content of network, provided high value-added, low cost of teaching resources, students were drawn together, constructed the new relationship between teaching and learning, innovation interactive teaching and collaborative teaching mode. Individualized teaching for large number of learners, in the Internet technology, big data analysis technology and cloud technology support had become a reality.

\section{Acknowledgements}

Ministry of Education CAXC-13A-20; Education Science Planning in Jilin province GH14333; Jilin Agricultural Science and Technology University 2015X096; Jilin Agricultural Science and Technology University JGYB008.

\section{References}

[1] Information on http:// www.gov.cn.

[2] Information on http:// www.China Daily.com.cn.

[3] N. Liu, C. Wang: Internet Education: education reform in the mobile Internet era (Economic Publications, China 2015). (In Chinese)

[4] J. F. Zhang: People's Education, Vol. 7 (2015) No.13,p.72. (In Chinese)

[5] S. Liu: Enterprise Reform and Management, Vol. 9 (2015) No.15, p.47. (In Chinese)

[6] Y.M. Wang: The Guide of Science \& Education, Vol.3 (2015) No.12, p.13. (In Chinese)

[7] X. Lin:Computer Knowledge and Technology(Academic Exchange), Vol.11 (2015) No.36, p.72. (In Chinese)

[8] R.J. Zheng, M.C. Zhang, Q.T. Wu: Journal of Computers, Vol.8 (2013) No.12,p.3134. 
[9] C.C. Chen, C.C. Wang:Journal of Computers, Vol.8 (2013)No.7, p.1633.

[10] J. Li:Frontiers of Education in China, Vol. 7 (2012) No.3, p.417. 